\title{
Primeiro registro das espécies de cigarrinhas-da-raiz da cana-de-açúcar Mahanarva spectabilis (Distant) e Mahanarva liturata (Le Peletier \& Serville) atacando canaviais na região de Goianésia (GO), Brasil
}

\author{
First record of the sugarcane froghoppers Mahanarva spectabilis (Distant) \\ and Mahanarva liturata (Le Peletier \& Serville) infesting sugarcane \\ plantations in the region of Goianésia (GO), Brazil
}

\section{Roberto Teixeira Alves ${ }^{1 *}$, Gervásio Silva Carvalho²}

RESUMO: As formas jovens da cigarrinha-da-raiz da cana-de-açúcar sugam as raízes, e os adultos sugam as folhas e injetam toxinas, causando necrose nos tecidos foliares. A espécie de cigarrinha mais citada em trabalhos científicos é a Mahanarva fimbriolata. Adultos de cigarrinha foram coletados em canaviais da Usina Jalles Machado, em Goianésia (GO). Estes foram montados, identificados e depositados na coleção da Pontifícia Universidade Católica do Rio Grande do Sul (PUCRS). A identificação foi feita pela genitália. Constatou-se tratar de Mahanarva spectabilis e Mahanarva liturata, consistindo-se no primeiro registro das espécies de cigarrinhas-da-raiz atacando os canaviais em Goianésia; no local, pensava-se que existia somente a espécie $M$. fimbriolata.

PALAVRAS-CHAVE: controle biológico; genitália; Mahanarva; pragas da cana.

\begin{abstract}
The young forms of the sugarcane froghopper suck the roots, and the adults suck the sap from leaves and inject toxins, thus causing necrosis in leaf tissues. The most cited species of sugarcane froghopper in scientific papers is Mahanarva fimbriolata. Adults of the froghopper were collected in sugarcane plant Jalles Machado, in Goianésia (GO). These have been put together, identified and deposited in the collection of Pontificia Universidade Católica do Rio Grande do Sul (PUCRS). Identification was conducted by the genitalia. We found there were Mahanarva spectabilis and Mahanarva liturata, consisting of the first record of this species of froghopper attacking sugarcane fields in Goianésia; in this place, only the species $M$. fimbriolata was considered to exist.
\end{abstract}

KEYWORDS: biological control; genitalia; Mahanarva; sugarcane pests. 
No Brasil, a cana-de-açúcar é cultivada em 8.523 .415 hectares, de onde se obtém uma produção de 672.156.957 toneladas; $45,15 \%$ dessa produção ficam em áreas do cerrado brasileiro (ІвGE, 2009).

A proporção de áreas colhidas de forma mecanizada, nas quais a cana não é queimada e onde se utiliza o termo cana crua, vem aumentando a cada ano. Em termos ambientais e de saúde pública, isso é muito favorável e deve ser incentivado. Porém, isso tem favorecido o aumento da população das cigarrinhas-das-raízes da cana em diversas regióes do país. O fato de não queimar a palhada, onde está situada boa parte dos ovos da cigarrinha, favorece o aumento desse inseto-praga nos canaviais. Por isso, deve-se aprender a conviver com esse tipo de inseto sem permitir que ele cause prejuízos econômicos ao produtor.

As formas jovens da cigarrinha-da-raiz (Mahanarva spp.) extraem grande quantidade de água e nutrientes das raízes. Os adultos sugam a seiva das folhas e injetam toxinas, causando necrose nos tecidos foliares. Com isso, o processo fotossintético é reduzido, e o canavial pode ficar totalmente seco com infestaçôes severas. A quebra da produtividade pode chegar a $50 \%$, na cana colhida no final de safra, e a $10 \%$, quando colhida no início da safra (Dinardo-Miranda, 2005).

Conforme Paladini; Carvalho (2007), Mahanarva foi descrito por Distant (1909), que elegeu como espécie-tipo Mahanarva indicata Distant, 1909. O gênero é constituído atualmente por 41 espécies neotropicais, agrupadas em dois subgêneros, Mahanarva s. str. e Ipiranga Fennah, 1968.

Segundo Carvalho; WebB (2005), algumas espécies têm características comuns dentro dos subgêneros, como a tégmina proporcionalmente mais alongada em Mahanarva (Ipiranga).

A espécie de cigarrinha-da-raiz da cana-de-açúcar mais citada em trabalhos científicos é a Mahanarva fimbriolata (STAL, 1854). Porém, muitas vezes, alguns pesquisadores não se preocupam em confirmar a espécie que realmente está atacando o canavial onde o experimento foi desenvolvido.

Ao se conduzir, durante três anos consecutivos, experimentos sobre o controle biológico de cigarrinha-da-raiz em canaviais da Usina Jalles Machado (latitude 1513'00,64”S, longitude $48^{\circ} 57^{\prime} 43,27^{\prime \prime} \mathrm{O}$; altitude de 614 metros) no município de Goianésia (GO), adultos de cigarrinhas foram coletados em janeiro de 2011, os quais foram devidamente montados em alfinetes entomológicos, e identificados conforme descrito nos próximos parágrafos pelo entomologista/taxonomista em Hemiptera, Auchenorrhyncha, Cercopidae, professor doutor Gervásio Silva Carvalho, da Pontifícia Universidade Católica do Rio Grande do Sul (PUCRS). Os adultos foram depositados na coleçâo entomológica do Museu de Ciências e Tecnologia da PUCRS.

Na identificação feita através das peças da genitália, já que externamente os adultos são semelhantes, constatou-se tratar de Mahanarva spectabilis (Distant, 1909) e Mahanarva liturata (Le Peletier; Serville, 1825), consistindo-se no primeiro registro das espécies de cigarrinhas-da-raiz da cana-de-açúcar atacando os canaviais na regiâo de Goianésia; no local, considerava-se que só existia a espécie $M$. fimbriolata. A mesma dúvida já havia surgido com cigarrinha-das-pastagens atacando Brachiaria brizantha cv. Marandu nos estados do Tocantins, Goiás, Pará e no Distrito Federal, onde foi detectada a presença de M. spectabilis atacando as pastagens, e não de $M$. fimbriolata, como até então era atribuído (PaulaMoraes et al., 2006).

Muitas espécies de cercopídeos têm variação no padrão alar. Esta variação possibilitou que espécimes de M. liturata, M. fimbriolata e M. spectabilis tivessem semelhanças no padrão das tégminas, podendo somente ser diferenciadas pelas peças da genitália do macho, principalmente do parâmero.

Seguem comentários que permitem distinguir as duas espécies em questão, principalmente no tocante a peças da genitália do macho.

\section{Mahanarva (Mahanarva) spectabilis (Distant, 1909)}

Diagnose. Coloração geral muito variada, porém frequentemente com cabeça e pronoto castanho-avermelhados; tégminas variando de negro a vermelho, passando pela presença de faixas longitudinais negras em fundo avermelhado (Fig. 1A).

Mahanarva (Mahanarva) liturata (Le Peletier; Serville, 1825)

Diagnose. Coloração geral avermelhada, com cabeça e pronoto frequentemente castanho-avermelhado mais escuro e com manhas negras; tégminas com fundo vermelho-alaranjado e com faixas longitudinais negras.

As duas espécies são mais precisamente diferenciadas, principalmente os espécimes com padrôes de faixas semelhantes (Fig. 1A), pelas peças da genitália do macho. Em M. spectabilis, os parâmeros são sub-retangulares, com
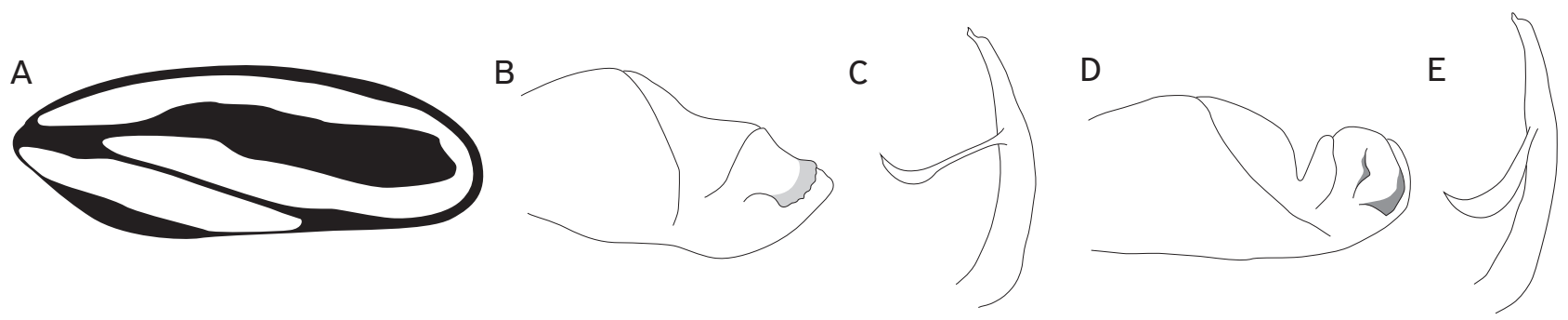

Figura 1. Mahanarva spectabilis. A: tégmina direita; B: parâmero esquerdo; C: edeago; Mahanarva liturata. D: parâmero esquerdo; E: edeago. 
elevação dorsal não pronunciada; em vista lateral externa, o ápice é triangular e o dente subapical tem forma de cunha, com a margem levemente serreada (Fig. 1B); edeago com processo dorsal curvo na extremidade e em forma de foice (Fig. 1C). Em M. liturata, os parâmeros são sub-retangulares, com elevação dorsal pronunciada; em vista lateral externa, o ápice é arredondado e o dente subapical é voltado para baixo, com subesclerotização posterior (Fig. 1D); edeago com processo dorsal curvo em forma de foice e de mesma largura em toda a extensão (Fig. 1E).

O objetivo desta nota é comunicar que as cigarrinhas-da-raiz da cana-de-açúcar, $M$. spectabilis e $M$. liturata, estáo presentes e atacando os canaviais na região de Goianésia, local onde se constatava que existia somente $M$. fimbriolata. Outro ponto importante é enfatizar a necessidade do envio de material para taxonomistas sempre confirmarem a espécie em estudo.

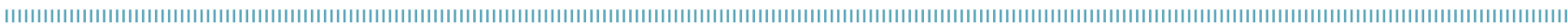

\section{REFERÊNCIAS}

CARVALHO, G.S.; WEBB, M.D. Cercopid spittlebugs of the New World (Hemiptera, Auchenorryncha, Cercopidae). Sofia: Pensoft, 2005. $271 \mathrm{p}$.

DINARDO-MIRANDA, L.L. Nematóides e pragas de solo em cana-de-açúcar. Informações Agronômicas, 110 , p.25-32, 2005.

Instituto Brasileiro de Geografia e Estatística - IBGE. Sistema IBGE de Recuperação de Dados (SIDRA). 2009. Disponível em: $<$ www.sidra.ibge.gov.br>. Acesso em: 08 jun. 2011.
PALADINI, A.; CARVALHO, G.S. Descrição de três novas espécies de Mahanarva (Hemiptera: Cercopidae: Ischnorhininae). Iheringia. Série Zoologia, Porto Alegre-RS, v. 97(1), p. 57-66, 2007.

PAULA-MORAES, S.V.; CARVALHO, G.S.; RAMOS, A.K.B.; AUD, A.M.; TAKADA, S.; BARCELLOS, A.O. Ocorrência da cigarrinha-daspastagens Mahanarva spectabilis (Distant, 1909) em gramíneas forrageiras e sua distribuição em áreas de Cerrado e na Amazônia Legal. In: REUNIÃO ANUAL DA SOCIEDADE BRASILEIRA DE ZOOTECNIA, 43, 2006, João Pessoa. Anais. Sociedade Brasileira de Zootecnia. CD-ROM. 2006. 5p. 